\title{
AS ASSOCIAÇÕES MÉDICO-ESPÍRITAS E A DIFUSÃO DE SEU PARADIGMA DE CIÊNCIA E ESPIRITUALIDADE
}

Rogers Soares*

Resumo: Este artigo tem por objetivo principal analisar a ação e o discurso produzido pelos "médicos espíritas" associados à AME-Brasil - Associação Médico-Espírita do Brasil. Destacamos também a história dessa associação e, tangencialmente, a de suas congêneres, assinalando o contexto em que essa história se insere, qual seja, o da crise da biomedicina e do avanço das chamadas "medicinas alternativas".

Palavras-chave: Espiritismo. Associação Médico-Espírita. “Medicina Alternativa”. Abstract: This article aims to analyze the action and the discourse produced by the "Spiritist Physicians" associated to AME-Brasil - Brazilian Medical Spiritist Association. The article also emphasizes the history of this association and, tangentially, of its congeners, highlighting the context in which this history has been inserted, i.e., the context of the biomedicine's crisis and of the advancement of the called alternative medicines.

Keywords: Spiritism. Medical Spiritist Association. "Alternative Medicine".

A competição pela hegemonia no campo da prática terapêutica atravessa os séculos. Toda a História é pontuada por conflitos entre um grupo que se arroga a exclusividade do conhecimento médico - supostamente superior e verdadeiro -, contra outros, classificados como charlatões (Sayd, 1988). No Brasil, a restrição do exercício da medicina aos diplomados tem encontrado inúmeros desafios. Entre os anos 1890 e 1940, especialmente, uma das preocupações constantes para muitos médicos foram as práticas e doutrinas espíritas imiscuindo-se na atividade de cura e de terapia. Nesse período, muitos profissionais da área da saúde formularam teorias para explicá-las e deslegitimá-las - o que não raramente assumia a forma de campanhas contra o espiritismo -, enquadrando-as, junto a tantos outros sistemas que concorriam com a medicina oficial, nos casos de "charlatanismo" (GIUMBELLI, 1997, v. 40, p. 36).

A eficácia dessas práticas nem chegava a ser objeto de discussão no âmbito da medicina acadêmica: era terminantemente negada. Argumentava-se que

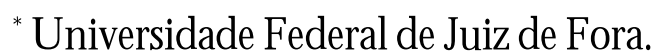


ela colocava pacientes sob responsabilidade de pessoas sem competência para tratálas; impedia a intervenção qualificada dos médicos (com seus saberes e suas práticas oficiais) e ainda podia ser diretamente prejudicial, agravando uma enfermidade. Esse tipo de "medicina" - "supersticiosa", "primitiva" e "irracional" - só podia existir em virtude da "ignorância" e do "misticismo" do povo, conjugados à falta de repressão por parte das autoridades competentes (GIUMBELLI, 1997, v. 40, p. 36).

A partir da década de 1940, de acordo com Emerson Giumbelli (1997, p. 267), a tensão entre a medicina acadêmica e o espiritismo parece ter se atenuado. Esforçando-se para alcançar legitimidade frente aos poderes públicos como uma religião, os espíritas, coordenados pela Federação Espírita Brasileira, foram gradativamente abandonando os traços que os identificavam à ciência médica formal e acadêmica, e paulatinamente intervindo no campo espiritual e moral. Daí a difusão de práticas que se destinavam a agir sobre espírito, como os "passes e as "desobsessões". O "físico" e o "material" só seriam atingidos, se assim o fossem, de modo tangencial, em virtude de sua ligação ao espírito.

Recentemente, porém, o espiritismo volta a ganhar evidência, sinalizando a retomada de uma perspectiva de "ciência espiritualizada". Médicos espíritas vêm propondo um novo paradigma na medicina que leva em conta a espiritualidade e seus corolários - chamam-no de paradigma médico-espírita. Coordenados pela AME-Brasil - Associação Médico-Espírita do Brasil, criada na cidade de São Paulo, em 1995 -, esses profissionais têm feito pesquisas, congressos e campanhas, buscando implementar mudanças na base da medicina oficial; fato que vem crescendo no Brasil e despertando a atenção de pesquisadores no país e no exterior.

A proposta do paradigma médico-espírita deve ser entendida num contexto no qual, atualmente, a "medicina convencional", malgrado todos os seus avanços e seus sucessos, atravessa uma grave crise, ao passo que muitas "medicinas alternativas" ${ }^{1}$ já fazem parte da realidade de grande número de

\footnotetext{
${ }^{1}$ Segundo Madel T Luz (2005, p. 146), esse termo diz respeito "não apenas as medicinas tradicionais das culturas nacionais (ou mesmo regionais), como também as medicinas tradicionais provindas do Oriente, e a medicina homeopática". A autora apresenta a definição do termo "medicina alternativa", como ela própria enfatiza, segundo a Organização Mundial de Saúde (em 1962).
} 
pessoas. ${ }^{2}$ Essas "medicinas" propõem uma terapêutica que foge à racionalidade do modelo médico dominante, sobre o qual se fundamenta a moderna prática médica, qual seja, o modelo biomédico, cuja ênfase é o estudo isolado de órgãos e tecidos (LUZ, 2005, p. 145). Essas "práticas alternativas", como também são chamadas, adotam uma postura holística e naturalística diante da saúde e da doença, opondo-se, dessa forma, à medicina especializada, tecnológica e mercantilizada (QUEIROZ, 2000, p. 364).

Há de se destacar também que cresce o número de estudos científicos a respeito do efeito da religiosidade sobre a saúde. Além disso, vários médicos vêm associando a seus trabalhos os princípios de suas crenças religiosas, como, por exemplo, os médicos católicos, que fundaram a Associação Católica Médica.

No encalço dessas críticas à "medicina oficial", proclamando a união entre a religião e a ciência, a fé e a razão, os médicos espíritas reivindicam, de modo bastante articulado, um espaço dentro da própria ciência médica, tentando escapar aos epítetos que acompanham as práticas de cura espírita, como o de "supersticiosa", "primitiva" e "irracional". Visam também coordenar ações "anticharlatanismo", i.e., desmascarar pessoas não espíritas e sem formação médica que se dizem capazes de realizar "milagres".

De acordo com a revista Saúde \& Espiritualidade, a Associação MédicoEspírita do Brasil tem por missão básica:

(...) contribuir para o estudo e a pesquisa científica no âmbito da Medicina e do Espiritismo, promover a difusão do paradigma médico-espírita, através do ensino e dos meios de comunicação, de livros e outras publicaçoes; contribuir para a implantação desse paradigma, tanto nos cursos de formação médica, quanto em outros; e incentivar o médico espírita no cumprimento de sua missão humanitária, apoiando as instituições beneficentes que visem à melhoria da saúde da coletividade, sobretudo, a dos mais carentes (NOBRE, 2004, p. 4$5)$.

${ }^{2}$ De acordo com Luz (2005, p.157), no Brasil, "mesmo os pacientes que se tratam pela medicina convencional frequentemente buscam as medicinas espirituais da umbanda, do candomblé e dos centros kardecistas, utilizando-as sincreticamente como forma terapêutica popular".

Debates do NER, Porto Alegre, ANo 10, N. 15, P.129-150, JAN./JUn. 2009 


\section{UM POUCO DA HISTÓRIA E DA ORGANIZAÇÃO DAS AMES}

Associadas à AME-Brasil, existem, atualmente, 36 entidades - além da AMEInternacional -, presentes em várias cidades e Estados. Entretanto, antes do início da década de 1990, funcionavam apenas a AME-São Paulo, fundada em 1968, e a AME-Minas Gerais, em 1986.

A ideia da criação de semelhante instituição partiu de um grupo de médicos que, na residência do médium Spartaco Ghilardi, em São Paulo, passou a reunir-se semanalmente, nos idos de $1967 .{ }^{3}$ Nessas reuniões, chegavam mensagens de "espíritos" que exortavam o grupo a aplicar, na ciência médica, os conhecimentos reunidos pela doutrina espírita, de modo a estabelecer "as bases do hospital e da assistência médica do futuro” (CAMPOS, 2008, p.4).

No correr do ano de 1967, foram realizados contatos, estudos e exposições de temas que aliavam a Medicina à Doutrina Espírita, preparando, assim, o terreno para a I Concentração de Médicos Espíritas, que teve assento na cidade de Araras, Estado de São Paulo, no dia 13 de janeiro de 1968. Nesse evento, foram planejados os estatutos e marcada a data para a edificação da primeira entidade de médicos espíritas do Estado de São Paulo e do país. Conforme o artigo comemorativo dos 40 anos da AME-SP, publicado no jornal Folha Espírita, "muitas mensagens do Plano Espiritual, de regozijo, foram enviadas do Plano Espiritual, principalmente por Bezerra de Menezes ${ }^{4}$ e Batuíra ${ }^{5}$, saudando a iniciativa”.

\footnotetext{
${ }^{3}$ Portanto, embora difundida apenas na década de 1990, a primeira AME data da década de 1960, justamente quando o tema da secularização, na academia, estava na ordem do dia.

${ }^{4} \mathrm{O}$ médico Adolfo Bezerra de Menezes nasceu na antiga Freguesia do Riacho do Sangue (atual Jaguaretama), no Estado do Ceará, em 1831, e faleceu no Rio de Janeiro, em 1900. Considerado como o "precursor do Espiritismo no Brasil", Bezerra de Menezes continua, segundo os espíritas, atuando na causa espírita brasileira, mesmo encontrando-se em um "plano" diverso do nosso, sendo "requisitado", principalmente, em matéria de cura e terapia, aplicadas nos centros e hospitais espíritas.

${ }^{5}$ Antônio Gonçalves da Silva, conhecido como Batuíra, nasceu em Portugal, na Freguesia de Águas Santas, hoje integrada ao Conselho da Maia, em 1839, e faleceu em São Paulo, em 1909. Fundador do Grupo Espírita Verdade e Luz e da Tipografia Espírita, é considerado um dos pioneiros do Espiritismo no Brasil.
} 
A fundação da Associação Médico-Espírita de São Paulo (AME-SP) se efetivou, então, em 30 de março de 1968, na biblioteca do Hospital São Lucas, na capital paulista, "sob as benções de Bezerra de Meneses e Batuíra" ${ }^{6}$ No que se refere ao perfil da associação, a AME-SP estabeleceu-se como:

(...) uma organização científica, cultural, religiosa, beneficente e sem fins lucrativos, com o objetivo de aprofundar o estudo da Doutrina Espírita, codificada por Allan Kardec, e de sua fenomenologia, tendo em vista as suas relações, integração e aplicação nos campos da Filosofia, da Religião e das Ciências, principal-mente da Medicina (CAMPOS, 2008, p. 4).

Nos anos posteriores, a AME concentrou-se na realização de palestras e simpósios, dirigidos aos profissionais da saúde, versando sobre "aspectos científicos" de questões básicas do espiritismo, tais como a sobrevivência da alma, a comunicabilidade dos espíritos e os processos de saúde-doença. A associação prima em dizer que, logo na primeira década de exercício, contou com convidados internacionais, como o professor indiano Hamendras Banerjee e o médico norte-americano Ian Stevenson, ambos pesquisadores acerca da encarnação.

A partir de março de 1984, a AME-SP passou a publicar o Boletim MédicoEspirita, com textos e artigos da pena de seus membros. Realizou também, na mesma década, três simpósios brasileiros de Parapsicologia, Medicina e Espiritismo (Sibrapame), no auditório da Cidade Universitária, em São Paulo. Em fins da década 1980 e início da década de 90, seguindo os passos dessa instituição pioneira, novas associações começaram a surgir em outras cidades e estados.

Em 1991, aconteceria o primeiro congresso espírita de âmbito nacional - o Mednesp; evento que, desde então, vem sendo realizado bienalmente. Durante a realização do $3^{\circ}$ Mednesp, em 1995, teve origem a Associação MédicoEspírita do Brasil - instituição que congregaria as AMEs, que naquele momento já haviam se multiplicado pelo país. Naquela década, também crescera o número

\footnotetext{
${ }^{6}$ Segundo os espíritas, existe um intenso intercâmbio entre o "plano espiritual" e o "plano carnal". "Espíritos superiores" inspiram ações no plano terrestre, até mesmo na descoberta de tecnologias, que muitas vezes tratar-se-ia de uma simples e grosseira "adaptação' para o "nosso mundo" da tecnologia já existente no "mundo espiritual".
}

Debates do NER, Porto Alegre, ANo 10, N. 15, P.129-150, JAN./JUn. 2009 
de atividades e de publicações; "livros e palestras trouxeram informações contundentes e evidências cientificas relacionadas à cura espiritual” (CAMPOS, 2008, p. 4). De acordo ainda com a articulista do jornal Folha Espírita, portas de universidades, em muitas cidades, foram abertas para a "inserção da espiritualidade como agente promotor de saúde” (CAMPOS, 2008, p. 4) - embora essa prática só viesse a ter uma frequência maior após a virada do milênio, complementa.

A realização dos congressos nacionais (Mednesp), a partir de 1991, foi, portanto, fundamental para o surgimento de outras AMEs. ${ }^{7}$ Se no início da década de 1990 só funcionavam, como já mencionado, a AME-São Paulo e a AME-Minas Gerais, em 1995, nove delas já participavam do evento, reunindo, então, seus esforços na constituição da entidade nacional. Assim, a AME-Brasil foi fundada pelas AMEs Bahia, Campina Grande, Ceará, Espírito Santo, Minas Gerais, Pernambuco, Piauí, Rio Grande do Norte e São Paulo. ${ }^{8}$ Com a concretização da AME-Brasil, foi criada, em 1999, a Associação Médico-Espírita Internacional (AME-I), durante a realização do II Congresso da Associação Médico-Espírita do Brasil, em São Paulo. Desde então, uma comissão composta por três médicos: Dra. Marlene Nobre (Brasil), Dr. Sabino Luna (Argentina) e Dra. Maria de La Gracia de Ender (Panamá) dirigem a entidade, tendo como presidente a Dra. Marlene Nobre.

A AME-I tem realizado vários eventos e estimulado a fundação de outras instituições ligadas à saúde, como a Associação dos Profissionais Espíritas da Saúde (APES) de Londres e a de Montréal. Em abril de 2008, foi fundada ainda a Associação Médico-Espírita de Cuba. ${ }^{9}$

Em relação ao trabalho desenvolvido pela AME-Brasil, Marlene Nobre, presidente, avalia que, não obstante seja ela uma "plantinha pequenina" diante de um grande campo a ser cultivado, em muitos aspectos a entidade avançou. Segundo a presidente:

\footnotetext{
${ }^{7}$ A partir de 1997, a AME-Brasil passou a ser responsável pela realização dos congressos nacionais, tendo trazido, desde 2003, convidados estrangeiros, como os Professores Drs. Harold Koenig, Amit Goswami e Peter Fenwick cf. http://www.amesaopaulo.org.br/novo/index.php? option= com_content\&task=view\&id=12\&Itemid=28

${ }^{8} \mathrm{Cf}$. AME-Brasil: dez anos de ideal e sacrifício http://www.folhaespirita.com.br/anteriores.php

${ }^{9} \mathrm{Cf}$. Ame-international. Histórico. http://amesaopaulo.org.br/novo/index.php?option $=$ com_content $\&$ task=view \&id=12\&Itemid=28 .
} 
Temos um trabalho de muito ideal e sacrifício. Claro que ainda falta muito, principalmente na base sólida e estrutural da AME-Brasil e de suas regionais, mas conseguimos formar uma massa crítica, extrapolando o campo médicoespírita, sendo chamados às universidades. E ter extrapolado o meio espírita é uma façanha (CAMPOS, 2008, p. 4).

Parte disso se deve, de acordo com Marlene, ao fato de a entidade "ter sempre conversado com outras culturas e religiões, respeitando-as". "Apesar de a mídia ainda torcer o nariz para o nosso trabalho, temos conseguido, aos poucos, quebrar certos tabus e mostrar que um novo paradigma está surgindo", diz. "Em termos de conceito e necessidade de implantação de saúde e espiritualidade, realmente avançamos bastante”, (CAMPOS, 2008, p. 4) complementa.

\section{A CRISE DA BIOMEDICINA E A EMERGÊNCIA DAS MEDICINAS ALTERNATIVAS}

Para entendermos melhor o empenho dos médicos-espíritas na difusão do paradigma espírita, convém traçarmos, em breves linhas, o atual estado do campo da medicina; o contexto é fundamental para entendermos a propagação deste. Antes, porém, convém trazermos à baila, sumariamente, alguns dos aspectos dessa ciência.

O termo biomedicina tem sido, amiúde, empregado nos trabalhos antropológicos para designar a medicina moderna, remetendo à estrutura institucional da medicina no Ocidente. Os fundamentos dessa ciência alicerçam-se na mecânica clássica; assim, os médicos supõem poder isolar as partes do todo para compreendê-las e, adiante, reintegrá-las ao seu mecanismo original - a leitura do todo é o resultado da leitura das partes isoladas. Ostentam um discurso de caráter universal e generalizante, deixando os casos individuais em plano secundário.

Na perspectiva biomédica, as doenças são entendidas como se fossem "coisas, de existência concreta, fixa e imutável, de lugar para lugar e de pessoa para pessoa." (CAMARGO JR, 2005, p. 186.). Expressam-se por um conjunto de sinais e sintomas que são manifestações de lesões de uni ou multicausalidades, 
que alteram a morfologia e a dinâmica do corpo. Elas devem ser buscadas no âmago do organismo e corrigidas por algum tipo de intervenção concreta: terapêutica, medicamentosa ou cirúrgica (CAMARGO JR, 2005, p. 186).

A biomedicina, situando-se no âmbito das ciências naturais, busca trabalhar com dados físicos e quantificáveis. Fiel a esse objetivo, ela não leva em conta a subjetividade do adoecimento - a complexidade e a singularidade do sofrimento humano -, já que ela não pode ser objetivada e generalizada (GUEDES; NOGUEIRA e CAMARGO JR. 2006, p. 1095).

Diante do exposto acima, podemos entender um pouco melhor uma das faces da tão propalada crise da biomedicina - um tema frequentemente comentado não só pelos estudiosos da medicina mas também pela mídia, de uma maneira geral. Sobre este assunto, poucas saídas são apontadas, enquanto sobejam problemas levantados. Para Madel Luz (2005, p. 145), que define a situação da medicina como "uma crise nas suas dimensões ética, política, pedagógica e social”, os problemas mais recorrentes são: os programas de atenção médica precários, a ênfase na diagnose em detrimento da cura do sujeito doente, a relação médico-paciente determinada pelas leis do mercado, os crescentes custos dos tratamentos e exames, a competição entre as especialidades médicas e os demais profissionais de saúde, os conflitos entre médicos e os cidadãos que estão em busca de atenção à saúde, e a incapacidade de se formarem profissionais de saúde que sejam aptos à resolução dos problemas na área de saúde (LUZ, 2005, p. 145).

Entre as soluções frequentemente apontadas para essa crise estão, entre outras, maiores investimentos no setor, vontade política, refinamento técnicoadministrativo, melhor estruturação do sistema e melhorias na gestão. No entanto, a despeito da validade dessas medidas, urge solucionar uma questão ainda mais importante e polêmica; a crise do próprio paradigma biomédico. Não são poucos os estudiosos que criticam ou já criticaram o "reducionismo" organicista da medicina vigente; dentre eles podemos citar os trabalhos de Clavreul (1983) e de Foucault (1977) - já clássicos -, e, dentre os mais recentes, Camargo Jr. (2007) e Queiroz (2000).

Para esses autores, a crise da medicina ocidental moderna refere-se, como antes aludido, à crise de seu paradigma dominante, inteiramente identificado com o positivismo. Fundamentada neste, a biomedicina não leva em conta, 
tanto na determinação do seu objeto de conhecimento como na maneira de abordá-lo, o papel da sociedade, da cultura, da comunidade científica e da própria história. Supõe-se que, da mesma forma que qualquer objeto natural, a saúde e a doença possam ser explicadas exclusivamente pela interação mecânica das diferentes partes do organismo humano.

Segundo Queiroz, a perda da visão unificadora do paciente, e deste com o seu meio, começou a ocorrer com a Revolução Industrial, atingindo o paroxismo no século XX. Trata-se, portanto, de um fenômeno recente e sem paralelo na história do ocidente. A singularidade desse fenômeno, adverte o autor, se torna bastante evidente quando o sistema médico em questão é confrontado com outros sistemas nãoocidentais, a exemplo da Acupuntura e da medicina Ayurvédica; ou ainda com os sistemas populares da África, Ásia ou América Latina (QUEIROZ, 2000, p. 314). Esses sistemas têm em comum o pressuposto de que a saúde e a doença dependem do relacionamento tanto das diferentes partes do organismo entre si como deste com o seu contexto sociocultural.

Camargo chama à atenção ainda para a seguinte contradição: nem todas as manifestações da doença podem ser explicadas a partir do modelo doença/ lesão e seus correspondentes; assim, aquelas que não se enquadram nos referenciais da biomedicina tornam-se um problema para o diagnóstico, colocando em xeque o saber médico. Nesse caso, os sintomas físicos persistem sem que o médico possa detectar uma doença.

Para Camargo e Queiroz, autores sintonizados com a antropologia, a biomedicina ignora o fato de que o sofrimento seja uma experiência que envolve uma série de questões que vão além do biológico, já que se referem a questões psicológicas, culturais e sociais. Na maioria das vezes, os sintomas subjetivos não são levados em conta ou, mesmo, não se sabe como lidar com eles. As doenças não são vistas - como deveriam ser, na visão desses estudiosos - como construções, ficções criadas e categorizadas por homens, mas como entidades efetivamente concretas. Estas se apresentam e cabe ao médico identificá-las, encontrar a lesão e, parafraseando Foucault (1997), dar "visibilidade àquilo que está invisível”. Enquanto os referenciais teóricos do médico são os acima citados, o sofrimento do paciente torna-se irrelevante; "quando a doença passa a ser 'real' o paciente virtualiza-se” (GUEDES; NOGUEIRA; CAMARGO JR., 2006 p. 1096). 
A necessidade de uma abordagem biopsicossocial, como vimos, é frequente na prática discursiva da medicina. Entretanto, como Camargo nos lembra, existe uma total primazia do campo biológico sobre os demais: "Categorias fundamentais no que concerne ao adoecer como, por exemplo, SOFRIMENTO, SAÚDE, HOMEM (no sentido de "ser humano"),VIDA, CURA encontramse perdidas nas brumas do imaginário ou empurradas para o terreno da metafísica, pois esse campo não é considerado objeto da física clássica" (apudGUEDES; NOGUEIRA; CAMARGO JR., 2006 p. 1096).

Para Queiroz, a presença hegemônica de uma medicina de custos crescentes baseada no hospital e na alta tecnologia em países como o Brasil, cuja grande maioria populacional é subalimentada e possui escasso controle ambiental, é muito irracional. Ehrenreich acrescenta ainda que o aumento do nível da atividade médica numa sociedade contemporânea, não corresponde a um aumento do nível de saúde da população como se esperaria (apudQUEIROZ, 2000). O que se verifica de fato é que enquanto a alocação de recursos para a área médica na maioria dos países desenvolvidos tem se multiplicado a partir dos anos 50 , os ganhos em saúde tem sido irrisórios nas duas últimas décadas. Além disso, existem as doenças provocadas diretamente pela ação da intervenção médica, ou seja, as doenças iatrogênicas.

A emergência, no campo da saúde coletiva, de novas abordagens para se pensar o adoecimento, tais como a clínica ampliada, a humanização do atendimento, as discussões sobre a integralidade das ações de saúde e a produção do cuidado com vistas à transformação do modelo tecnoassistencial são tentativas de superar este modelo reducionista vigente na medicina atual. Concomitantemente a estas propostas, tem-se observado nos últimos anos uma crescente demanda das medicinas ditas alternativas em nossa sociedade, principalmente a partir das duas últimas décadas do século passado.

Essas terapias são em sua maioria orientais. Elas defendem formas simplificadas e não invasivas no tratamento das doenças, a utilização de medicamentos provenientes de produtos naturais (não químicos) e uma proposta ativa de promoção da saúde, diferente do preventivismo médico, pautado no combate às doenças. Nesse caso, o naturismosignifica não apenas a rejeição da medicina 
especializada e tecnificada, por ser invasiva, iatrogênica, portanto antinatural, mas também a afirmação da força curativa da naturezae da eficácia maior das terapêuticas provenientes da natureza (NOGUEIRA; CAMARGO JR. 2007, p. 856). A autora Madel Luz resume:

A busca social de culturas médicas orientais, intensificada a partir dos anos 70, sobretudo das medicinas chinesa e hindu, com suas visões da saúde do homem ditas holistas ou integrais, mas de fato profundamente espiritualizadas, é sintoma de um abalo sísmico de natureza ideológica que tem se mantido e propagado desde então na cultura ocidental, com maior ou menor intensidade nacional ou conjuntural (...) Esse abalo atinge a cosmovisão que informa a medicina científica moderna, sua concepção tecnicista e atomizante do homem e de suas doenças, concepção baseada na física clássica herdada de Newton e na visão dualista (corpo/alma) do ser humano herdada de Descartes (apud NOGUEIRA; CAMARGO JR. 2007. p. 850).

Completando este mosaico de sistemas medicinais que concorrem com a biomedicina, convém lembrar que no Brasil, de acordo com a referida autora, a busca pelas medicinas espirituais da umbanda, do candomblé e dos centros kardecistas, utilizados sincreticamente como forma terapêutica popular, é frequente mesmo pelos pacientes que se tratam através da medicina convencional (LUZ, 2005, p. 157).

\section{"UMA NOVA MEDICINA PARA UM NOVO MILÊNIO"}

O título desta seção, tomado emprestado de um artigo espírita, revela-nos o entusiasmo dos médicos espíritas nesses últimos anos. A leitura que fazem deste momento é a de um campo fértil para a ação. Imbuídos de uma visão teleológica e fatalista, peculiar à doutrina espírita, ${ }^{10}$ os médicos espíritas vêm enxergando, nos acontecimentos recentes da medicina - crise do paradigma

${ }^{10}$ Os médicos espíritas acreditam que é chegada a hora da medicina espiritualizar-se, sob as benções dos espíritos iluminados - em particular, de Bezerra de Menezes -, que já vem, há algum tempo, preparando este momento.

Debates Do NER, Porto Alegre, ANo 10, N. 15, P.129-150, JAN./Jun. 2009 
biomédico e crescimento das medicinas holísticas -, prenúncios favoráveis para uma ação mais enérgica, mais meticulosa no sentido de estender os seus fundamentos de espiritualidade para essa ciência.

A crescente procura pelas medicinas alternativas - ou, parafraseando Queiroz, antes alternativas - vem ao encontro das aspirações dos médicos espíritas. A principal "vantagem" dessas medicinas em relação à biomedicina reside na sua compreensão do todo, ou seja, na sua interpretação do binômio saúde-doença, em que os aspectos psíquicos e físicos são indissociáveis na busca do restabelecimento do equilíbrio.

Os custos crescentes que a medicina convencional acarreta; somados aos seus fracassos em lidar com algumas doenças, como câncer, doenças do coração, hipertensão arterial, doenças psiquiátricas, entre outras que não se mostram tratáveis pela intervenção tecnológica baseada no modelo unicausal de doenças; além das novas doenças, males e causas de mortes que passam a ser cada vez mais relacionadas com as condições de trabalho e de vida num determinado contexto socioeconômico e cultural vêm tornando as medicinas alternativas uma realidade cada vez mais presente (QUEIROZ, 2000, p. 314). Ciente das dificuldades da biomedicina em relação aos desafios mencionados acima, os médicos espíritas têm se aproveitado da situação para difundir seus pressupostos como uma solução a esses impasses.

Fazendo coro a essas medicinas, os médicos espíritas vêm reforçando suas críticas ao "reducionismo" da biomedicina e defendendo uma espécie de abertura para as propostas holísticas que tomam de assalto a época em que vivemos. Enumerando pesquisas científicas que mostram a evidência de "algo além da matéria", os espíritas esperam chamar a atenção da comunidade acadêmica para as "realidades" de um "novo tempo" que se anuncia. Dando voz a presidente da AME Brasil, Marlene Nobre:

Cada vez mais, "minorias criativas" buscam a integração entre Fé e Razão, tendo em vista que é impossível compreender o mundo, o universo e o próprio ser humano, sem as luzes de um paradigma, de um modelo, que contemple todas as áreas das cogitações humanas. As revoluções conceituais da física, no século $X X$, muito contribuíram para essa nova visão da realidade, demonstrando que a 
matéria cedeu lugar à energia, o tempo é variável, o movimento descontínuo, a interconectividade não localizada, e a consciência é capaz de influir nos eventos, selecionando possibilidades. Nesse novo tempo, especialistas passaram a enxergar o ser humano de forma integral, conectado a uma imensa rede invisível, que engloba todas as coisas, do micro ao macrocosmo, e não têm nenhum pudor em reconhecer a complementaridade entre Ciência e Religião, valorizando a integração da Espiritualidade à vida humana. ${ }^{11}$

Acreditam, então, que é a própria ciência que sofre um processo de mudança em seus fundamentos, ainda que lento. Nesse sentido, autoridades internacionais não espíritas são evocadas como exemplo dessa incipiente mudança:

A obra do ilustre físico e humanista Fritjof Capra, especialmente, O Ponto de Mutação, está na vanguarda, em particular para a Medicina, com sua proposta de Assistência Holística à Saúde, que contempla o ser humano integral - MenteCorpo. Nessa luta por um novo modelo de saúde, engajou-se também o físico quântico, Amit Goswami, com sua teoria sobre a Consciência, exposta em sua obra, especialmente, O Universo Autoconsciente. Nela, ele sustenta que a Consciência está fora da matéria, sendo, na verdade, fonte criadora do mundo

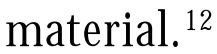

E prosseguem na enumeração de vários exemplos que, no imaginário espírita, se não corroboram de fato uma mudança, pelo menos indicam a possibilidade de abertura da comunidade cientifica para "realidades" que até então eram desconsideradas como objeto de especulação. À guisa de mais exemplos, Marlene Nobre lembra ainda o livro de Massaru Emoto - Messages from the Water - lançado após oito anos de investigação. Nele, o nipônico procurou mostrar que a água reage aos pensamentos e sentimentos humanos, formando cristais perfeitos ou não, conforme o tipo de irradiação.

${ }^{11} \mathrm{Cf}$. NOBRE, Marlene. A construção da espiritualidade na medicina. Disponível em: http:// www.amebrasil.org.br/html/pesq_const.htm. Acesso em jun. 2008.

${ }^{12}$ Id., ibid.

Debates do NER, Porto Alegre, ANo 10, N. 15, P.129-150, JAN./JUn. 2009 
Mais contundentes ainda, acrescenta Marlene Nobre, são as investigações de Experiências de Quase Morte (EQM), ${ }^{13}$ "cujos registros têm sido realizados por colegas médicos de diversos países, psicólogos e outros investigadores e que evidenciam a presença de um ser imaterial, presidindo o corpo humano". ${ }^{14}$ Para os médicos espíritas estas "experiências trazem subsídios importantes para validar a Terapêutica Complementar Espiritual e entreabrem novos campos para a pesquisa em medicina energética". ${ }^{15}$ Eles instigam, "como poderia o paciente experimentar uma clara consciência, fora do corpo, no momento em que o cérebro é afetado por uma parada cardíaca e o eletroencefalograma mostra-se plano?"16 A explicação sustentada por eles é que a EQM estaria ligada a um estado alterado de consciência, no qual a alma desprende-se do corpo, preservando, porém, a sua capacidade de percepção não sensorial, a sua identidade, cognição e emoção, independentemente do corpo inconsciente.

O protocolo de qualidade de vida da Organização Mundial da Saúde, de 1946, é frequentemente lembrado pelos espíritas como um avanço na superação

${ }^{13}$ Segundo Bruce Greyson (2007, p. 117), psiquiatra da Universidade da Virgínia, EUA, "quando algumas pessoas vivenciam um estado próximo do da morte, elas referem uma experiência profunda, na qual acreditam deixar seus corpos e ingressar em alguma outra esfera ou dimensão, transcendendo os limites do ego e as fronteiras convencionais do tempo e do espaço." O termo "near-death experiences" (NDE), de acordo com Greyson, foi cunhado pelo Psiquiatra e Filósofo Raymond A. Moody, que, estudando americanos que sobreviveram a essas experiências, delineou algumas características específicas, comumente referidas por eles. "Essas características, que definem uma experiência de quase-morte, tanto no meio acadêmico como na linguagem popular, incluem inefabilidade, ouvir o anúncio da própria morte, envolventes sentimentos de paz, ouvir um ruído, ver um túnel, sentir estar fora do corpo, encontrar-se com seres não-físicos, um ser de luz', realizar uma revisão da vida, retornar à vida, passar pela experiência de contar aos outros sobre essa vivência, os efeitos dessa vivência sobre a vida da pessoa que vivenciou uma EQM, ter novas visões da morte e a comprovação de conhecimentos não adquiridos por meio da percepção normal". Assim apresenta-nos Greyson, sumariamente, os estudos de Moody cuja obra, Life after life, data de 1975.

${ }^{14} \mathrm{Cf}$. NOBRE, Marle. O Paradigma Médico-Espírita, pontos de interseção entre Medicina e Espiritismo. http://www.allankardec.nl/portugues/palestras/marlene1.htm .

${ }^{15}$ Id., ibid.

${ }^{16}$ Id., ibid. 
do materialismo da medicina convencional ${ }^{17}$. Neste, ficou acordado que a "saúde é um estado de completo bem-estar físico, mental, social e não apenas a ausência de doença” ${ }^{18}$ Compreendendo que o bem estar mental deve contemplar também a dimensão espiritual, os médicos espíritas têm evocado esse protocolo, não raras vezes, como uma das justificativas não só para a realização de palestras e simpósios, como também para a abertura de cursos que relacionam medicina e espiritualidade nas universidades. ${ }^{19}$

Para os espíritas, "a higiene mental implica na elevação do pensamento e por isso todo aquele que se alimenta mentalmente de imagens e propósitos saudáveis, equilibrados e bons, atrairá para si afinidades nesse sentido e conseqüentemente se sentirá bem" ${ }^{20}$ Segundo eles, a sede do pensamento encontra-se no espírito. O pensamento é uma vibração capaz de agir no corpo e atrair vibrações outras que estejam na mesma "faixa". Dessa forma, a "qualidade" do pensamento é capital para a saúde; pois, além de ter efeito direto no organismo, o pensamento também atrai companhias espirituais afins, que podem ou prejudicar a saúde do "espírito encarnado" ou contribuir com a sua manutenção.

Não obstante o otimismo reinante existe uma grande preocupação no que tange ao exercício legal da medicina espírita, o que se justifica pelos percalços já vividos. Passemos mais uma vez a palavra a presidente da AME-Brasil:

17 “Trata-se de uma definição que foi sabiamente inspirada pelos benfeitores espirituais, mesmo tendo sido redigida nos conturbados momentos do pós-guerra", de acordo com Moura (2008, p. 153), articulista do jornal $O$ Reformador.

${ }^{18}$ ORGANIZAÇÃO DAS NAÇÕES UNIDAS (ONU). Constituiçã̃o da Organização Mundial da Saúde. Preâmbulo. Cf. http://www.unifran.br/mestrado/promocaoSaude/docs/ConstituicaodaWHO1946.pdf.

${ }^{19}$ Três universidades oferecem disciplina optativa relacionada à espiritualidade, são elas: Universidade Federal do Ceará, que oferta a disciplina "Medicina e Espiritualidade", coordenada pela AME-Ceará; a Faculdade de Medicina do Triângulo Mineiro, a disciplina "Saúde e Espiritualidade", coordenada pela AME-Triângulo Mineiro/Uberaba; e a Universidade Federal do Rio Grande do Norte, disciplina "Medicina, Saúde e Espiritualidade", ministrada pelo Departamento de Medicina Clínica dessa Universidade, com participação da AME-RN. Além dessas instituições, a Universidade Santa Cecília oferece o Curso de Extensão: "Bases da Integração Cérebro-MenteCorpo-Espírito", coordenado pela Associação Médico-Espírita de Santos. Cfhttp://www.amebrasil. org.br/portal/?q=node/54 .

${ }^{20}$ STEFANELLO, Vera. Evangelização espírita. 
Toda a terapia proposta pelo Espiritismo é complementar àquela que se pratica na Universidade. Então, o médico espírita não é um charlatão. Ele aprendeu nas universidades, ele faz uso do seu conhecimento, ele atualiza-se, ele especializa-se mas, também, sabe que precisa priorizar o espírito. Para isto, ele se utiliza da terapêutica complementar espírita, que é gratuita e existe em todos os centros e instituições espíritas, de modo que ele se utiliza da prece, da meditação, do passe, da sessão de desobsessão, das tarefas mediúnicas e, principalmente, daquilo que se chama o auto-encontro, que é o encontro da pessoa com ela mesma. Isto porque, na verdade, a cura é uma autocura. $\mathrm{O}$ médico é instrumento e o médium também. Por isso, se a pessoa não desejar, ela não se cura. (CAZETTA n. 611,2005$)$.

Para divulgar e, de certa forma, buscar legitimar o seu paradigma frente à sociedade, além dos canais da mídia e das comunicações científicas, a beneficência, velha conhecida, apresenta-se como uma forma estratégica. A proposta do recente Departamento de Solidariedade Humana, criado no final de 2007, é "inspirar ações no terreno prático do exercício Médico-Espírita", ${ }^{21}$ num trabalho conjunto entre Instituições Espíritas e AMEs.

As propostas de atividades são muitas, e estão apenas no início, dentre elas, destacamos: amparo aos jovens, com a participação de programas nas escolas, visando a inserção destes às "atividades construtivas"; amparo ao idoso, através, dentre outros, de orientação médica; prevenção à dependência química; visita aos encarcerados com programa de auxílio médico e espiritual; entre outras ações. ${ }^{22}$

Embora critiquem as "lacunas" deixadas pela medicina vigente - em virtude de sua redução à matéria -, os médicos-espíritas não se opõem aos conhecimentos dessa ciência. Face à crença na interação matéria/espírito, a "medicina da Terra”, como às vezes a chamam, faz-se necessária devido a sua proficiência no primeiro termo dessa relação, ou seja, na parte biológica. Para eles, é preciso reordenar o enorme conjunto de conhecimentos e tecnologias até hoje acumulados pela medicina convencional e articular a dimensão biológica com a espiritual na

\footnotetext{
${ }^{21} \mathrm{Cf}$. LOPES, Sérgio Luis da Silva. Departamento de solidariedade humana. http://www.amebrasil. org.br/portal/?q=node/31.

${ }^{22}$ Id., ibid.
} 
atenção à saúde. Daí o seu caráter de complementaridade. Isso visa também evitar a pecha de charlatão, por vezes apregoada a esse grupo, evitando problemas com as autoridades.

No rastro da crise da medicina e na experimentação de novas terapias, os médicos espíritas vão traçando suas ações para expandir seus fundamentos e estendê-los à ciência médica vigente. A reapropriação de novas pesquisas que contestam os fundamentos dessa ciência é um dos expedientes que os espíritas lançam mão. ${ }^{23}$ Os eventos que podem ser usados como "testemunho" da influência dos espíritos sobre a matéria ou da vida após a morte também são um recurso à parte. Um dos grandes exemplos, que já citamos, são as EQMs, que têm despertado o interesse não só da academia mas também da mídia em geral, sendo amplamente discutidas em jornais, revistas e filmes.

\section{CONSIDERAÇÕES FINAIS}

Vários trabalhos ${ }^{24}$ trazem como consenso, de acordo com Giumbelli (1997, p. 21), a ideia de que o espiritismo, no Brasil, em contraste com suas origens e desdobramentos europeus, seria ou teria se transformado numa "religião". Igualmente consente, é a associação do espiritismo a práticas terapêuticas, "como se 'espiritismo' e 'curandeirismo' participassem de um mesmo campo semântico e um mesmo território de realidade” (GIUMBELLI, 1997, v. 40, p. 33).

O mesmo antropólogo, discutindo a constituição do espiritismo no Brasil e, particularmente, no Rio de Janeiro, no período compreendido entre o final do século XIX e meados do XX, mostrou-nos os problemas que os espíritas enfrentaram com diversos grupos sociais e a estratégia para esquivarem-se de sua criminalização, posta em curso. Para o pesquisador, a concepção corrente de que espiritismo é religiãoseria efeito - usando as palavras de Birman (1997, p. 231)

\footnotetext{
${ }^{23}$ A física quântica é reiteradamente lembrada para a validação da fluidificação da água e dos passes magnéticos, uma vez que este novo paradigma científico preconiza - se nos é permitido expressar de forma tão simples - que a mente pode interagir com a matéria, já que ambas são formas de energia, sendo a última apenas um tipo de energia mais condensada.

${ }^{24}$ Como Warren $(1984,1986)$, Damazio (1994), Aubreé e Laplantine (1990).
} 
- de uma "conjunção peculiar, de um encontro de diferentes estratégias discursivas desenvolvidas por agentes sociais diversos"; o lugar de religião foi o que coube ao espiritismo, naquele momento de sua constituição no Brasil.

Ao sedimentar-se como uma crença, o espiritismo resigna-se, nos idos da década de 1940, ao monopólio de cura conquistado pela medicina acadêmica, eximindo-se, desse modo, da competição pela cura do corpo.

O que almejamos ressaltar é que a definição do espiritismo como prática religiosa é uma definição produzida e negociada, em que o contexto, como chave de análise, não pode ser negligenciado. Desejamos ainda sublinhar que, mesmo tendo adquirido uma feição social marcadamente "religiosa" no Brasil, o espiritismo jamais abdicou a referência simultânea à ciência e à religião na sua autodefinição, de acordo com Vasconcelos (2003, p. 94). Prosseguindo ainda no argumento do autor (2003, p. 120), a inserção simultânea nestes dois domínios,

[...] constitui um foco potencial de tensão, que se reacende periodicamente, quer em querelas internas, quer no relacionamento dos espíritas com pessoas e instituições exteriores. A dinâmica interna do movimento espírita brasileiro tem andado recorrentemente ligada a negociações e conflitos entre faç̧ões mais "religiosas" e facções mais "científicas".

Devemos considerar ainda que, atualmente, o espiritismo no Brasil experimenta uma "redefinição de sua identidade como movimento e religião" (LEWGOY, v. 8, 2008, p. 88). Segundo Lewgoy (2008, v. 8, p. 89) adentramos, no que se refere ao campo religioso brasileiro, numa nova época, na qual o espiritismo deixa de compor uma minoria - apresentando, ipso facto, um comportamento reativo - para compor uma alternativa religiosa. Nesse novo contexto, suas práticas e concepções perdem a unidade e passam a ser mais abertas, mais fragmentadas. Coeva a essas transformações, a reaproximação com a Medicina institucional vem granjeando cada vez mais espaço.

Assim, pretendíamos demonstrar como uma parcela intelectualmente expressiva dos espíritas - os profissionais associados às AMEs -, motivados 
por um certo Zeitgeist, ${ }^{25}$ reacenderam a velha discussão de que o espiritismo é também uma ciência e que tem muito a contribuir no campo da medicina. Para esses atores sociais, não mais se trata de uma "ciência" concorrente, mas de uma ciência complementar (pelo menos retoricamente) à medicina acadêmica. ${ }^{26}$

\section{REFERENNCIAS}

AME-Brasil: dez anos de ideal e sacrifício. Folha Espírita, São Paulo: FE- Editora Jornalística Ltda, jun. 2005. Disponível em: http://www.folhaespirita. com. br/anteriores.php Acesso em: 15 set. 2008.

ASSOCIAÇÃO MÉDICO-ESPÍRITA DO BRASIL. Histórico. Disponível em: http://amesaopaulo.org.br/novo/index.php?option=com_content\&task=view \&id=12\&Itemid $=28$. Acesso em: 15 set. 2008.

ASSOCIAÇÃO MÉDICO-ESPÍRITA INTERNACIONAL. Histórico. Disponível em: http://www.ameinternational.org/site/br/?q=node/1. Acesso em: 15 set. 2008.

CAMARGO JUNIOR, Kenneth Rochel de. A biomedicina. Physis - Revista de Saúde Coletiva, v.15, p. 177-201, 2005. Suplemento.

CAMPOS, Giovana. Associação médico-espírita de São Paulo. 40 anos inserindo o paradigma espiritual na prática clínica. Folha espírita, São Paulo: FE Editora Jornalística Ltda, ago. 2008.

\footnotetext{
${ }^{25}$ Segundo Marcelo Camurça (2000, p. 126), em face “[...] dos recentes desenvolvimentos sócio-culturais [...], podemos situar estas representações da 'medicina da alma' espírita dentro do paradigma holístico que articula o espiritual ao corpóreo numa perspectiva totalizante".

26 “Medicina da alma” é uma expressão que os espíritas usam, recorrentemente, em referência ao próprio metiér. É uma alcunha em tudo estratégica: demonstra a especificidade desta "medicina" - a alma e sua relação com o corpo; demarca a sua "superioridade" em relação à medicina ordinária - posto que a alma seria a "sede" de toda doença; deixa claro que não se trata de uma "medicina" concorrentecom a formal - já que sua especialidade, o espírito, não é contemplada pela academia - embora seja essa uma de suas aspirações.
}

Debates do NER, Porto Alegre, ANo 10, N. 15, P.129-150, JAN./Jun. 2009 
CAMURÇA, Marcelo Ayres. Entre o cármico e o terapêutico: dilema intrínseco ao espiritismo. Rhema, v.6, n.23, p. 113-128, 2000.

CAZETTA, Jenai Oliveira. Entrevista com Marlene Nobre. O imortal, jornal de divulgação espírita. Cambé, PR, ano 52, n. 611, jan. 2005.

CLAVREUL, Jean. A ordem médica: poder e impotência do discurso médico. São Paulo: Ed. Brasiliense, 1983.

DAMAZIO, S. Da Elite ao Povo: advento e expansão do espiritismo no Rio de Janeiro. Rio de Janeiro: Bertrand. Brasil, 1994.

FOUCAULT, Michael. Onascimento da Clínica. Tradução der Roberto Machado. Rio de Janeiro, Forense Universitária, 1977.

GIUMBELLI, Emerson Alessandro. Heresia, doença, crime ou religião: o Espiritismo no discurso de médicos e cientistas sociais. Revista de Antropologia, São Paulo, v. 40, n. 2, 1997.

- O cuidado dos mortos. uma história da condenação e legitimação do Espiritismo. Rio de Janeiro: Arquivo Nacional, 1997.

GREYSON, Bruce. Experiências de quase-morte: implicações clínicas. Revista psiquiátrica clínica, v. 34 supl.1, 2007, p. 116-125.

GUEDES, Carla Ribeiro; NOGUEIRA, Maria Inês; CAMARGO JR., Kenneth R. de. A subjetividade como anomalia: contribuições epistemológicas para a crítica do modelo biomédico. Ciência \& saúde coletiva, v. 11, n. 4, p.1093-1103, out./ dez. 2006.

LAPLANTINE, François; AUBRÉE, Marion. La table, livre et lessprits. naissance, évolution et atualité du mouvement social spirite entre France et Brésil. Paris: J. C. Lattès, 1990.

LEWGOY, Bernardo. A transnacionalização do espiritismo kardecista brasileiro: uma discussão inicial. Religião e sociedade, v. 28, n.1, jul. 2008, p.84-104.

LOPES, Sérgio Luis da Silva. Departamento de solidariedade humana, $A M E$ Brasil(siteda AME-Brasil). Disponível em: http://www.amebrasil.org.br/solidariedadehumana.htm. Acesso em: 12 fev. 2008. 
LUZ, Madel Terezinha. Cultura contemporânea e medicinas alternativas: novos paradigmas em saúde no fim do século XX. Physis, Rio de Janeiro, v.15, p.145176, Suplemento, 2005.

MOURA, Marta Antunes. Saúde e doença. O reformador, ano 126, n. 2153, p. 26-28. ago. 2008.

NOBRE, Marlene. Uma nova medicina para um novo milênio. Associação Médico Espírita do Brasil. (Org.). Medicina e Espiritismo. $1^{\text {a }}$ ed. São Paulo: Associação Médico-Espírita do Brasil, 2004. Disponível em: http://www.amebrasil. org.br/down/rev_POR.pdf. Acesso em: 15 set. 2007.

$A$ Construção da Espiritualidade na medicina. Disponível em: http://www.amebrasil.org.br/html/pesq_const.htm. Acesso em: 22 jan. 2008. NOGUEIRA, Maria Inês. Entre a conversão e o ecletismo: de como médicos brasileiros tornam-se "chineses". Tese (Instituto de Medicina Social) Universidade do Estado do Rio de Janeiro, Rio de Janeiro, 2003.

\& CAMARGO JUNIOR., Kenneth Rochel de. A orientalização do Ocidente como superfície de emergência de novos paradigmas em saúde. História, ciências, saúde-Manguinhos, v.14, n.3, p.841-861, jul./set. 2007.

ORGANIZAÇÃO DAS NAÇÕES UNIDAS (ONU). Constituição da Organização Mundial da Saúde. Preâmbulo. Nova Iorque, 22 jul. de 1946, p.1. Disponível em: http://www.unifran.br/mestrado/promocaoSaude/docs/ConstituicaodaWHO1946.pdf . Acesso: 20 set. 2008.

QUEIROZ, Marcos de Souza. O itinerário rumo às medicinas alternativas: uma análise em representações sociais de profissionais da saúde. Cadernos de Saúde Pública, Rio de Janeiro, v. 16, n. 2, 2000.

. O paradigma mecanicista da medicina ocidental moderna: Uma perspectiva antropológica. Revista de Saúde Pública, São Paulo, v. 20, n. 4, 1986.

SAYD, Jane Dutra. Mediar, Medicar, Remediar: aspectos da terapêutica na medicina ocidental. Rio de Janeiro: EdUERJ, 1988. 
STEFANELLO, Vera. Evangelização espírita. Disponível em: http://www.free webs.com/vstefanello/aulahigiene.htm. Acesso em: 22 jan. 2007.

VASCONCELOS, João. Espíritos Clandestinos: Espiritismo, pesquisa psíquica e antropologia da religião entre 1850 e 1920. Religião e Sociedade, Rio de Janeiro, v.23, n.2, 2003. p. 94.

WARREN Jr, Donald. A medicina espiritualizada: a homeopatia no Brasil do século. XIX, Religião e Sociedade, Rio de Janeiro, v. 13, n.1, 1986. . A terapia espírita no Rio de Janeiro por volta de 1900, Religião e Sociedade, v. 3, n. 11, 1984. 